\title{
Intestinal Microbiota-Kidney Cross Talk in Acute Kidney Injury and Chronic Kidney Disease
}

\author{
Sanjeev Noel ${ }^{a}$ Maria N. Martina-Lingua ${ }^{b}$ Samatha Bandapalle ${ }^{a}$ \\ Jennifer Pluznick ${ }^{c}$ Abdel Rahim A. Hamad ${ }^{b}$ Daniel A. Peterson ${ }^{b}$ Hamid Rabb $^{a}$ \\ Departments of a Medicine, ${ }^{b}$ Pathology and ${ }^{c}$ Physiology, School of Medicine, Johns Hopkins University, \\ Baltimore, Md., USA
}

\section{Key Words}

Intestinal microbiota · Acute kidney injury · Chronic kidney disease - Gut

\begin{abstract}
The pathophysiology of acute kidney injury (AKI) involves multiple and overlapping immunological, biochemical, and hemodynamic mechanisms that modulate the effects of both the initial insult and the subsequent repair. Limited but recent experimental data have revealed that the intestinal microbiota significantly affects outcomes in AKI. Additional evidence shows significant changes in the intestinal microbiota in chronic kidney disease patients and in experimental AKI. In this minireview, we discuss the current status of the effect of intestinal microbiota on kidney diseases, the immunomodulatory effects of intestinal microbiota, and the potential mechanisms by which microbiota can modify kidney diseases and vice versa. We also propose future studies to clarify the role of intestinal microbiota in kidney diseases and to explore how the modification of gut microbiota may be a potential therapeutic tool.

(c) 2014 S. Karger AG, Basel
\end{abstract}

Changing Paradigms in Acute Kidney Injury: From Mechanisms to Management - Proceedings of the 5th Annual UAB-UCSD O'Brien Center Symposium (San Diego, Calif., USA, March 4, 2014).

\section{KARGER}

E-Mail karger@karger.com

www.karger.com/nec

\section{Introduction}

Microbes are abundant in the human body. In fact, up to 100 trillion microbe cells are found in the human body, outnumbering human cells by 10 -fold and encoding 100 fold more unique genes than found in the human genome. Most of these microbes live in the gut, and metagenomic sequence studies have shown that between 1,000 and 1,150 of the most prevalent bacterial species are shared by humans, whereas roughly 160 of these are harbored individually by each person [1]. Extensive studies aided by recent technological advancements and innovative experimental approaches have demonstrated links between intestinal microbiota and human health. This has also led to a growing interest in understanding intestinal microbiota in kidney diseases. This can be appreciated from the fact that a broad PubMed search with the key words 'kidney disease' and 'intestinal microbiota' led to 12 items, 9 of which were published in 2013-2014 (table 1). However, only a small subset of these studies represent original research work investigating intestinal microbiota in animal models of kidney diseases or in human kidney diseases.

Ischemia-reperfusion injury and nephrotoxin-induced acute kidney injury (AKI) are significant problems in native and transplanted kidneys and involve multiple 
Table 1. Publications on intestinal microbiota and kidney diseases

\begin{tabular}{|c|c|c|c|c|c|c|}
\hline No. & Title & $\begin{array}{l}\text { Or- } \\
\text { ganism }\end{array}$ & $\begin{array}{l}\text { Kidney } \\
\text { disease }\end{array}$ & Year & Article type & $\begin{array}{l}\text { Ref. } \\
\text { No. }\end{array}$ \\
\hline 1 & $\begin{array}{l}\text { Human microbiota characterization in the course of renal } \\
\text { transplantation }\end{array}$ & Human & Transplant & 2014 & Original research & 16 \\
\hline 2 & $\begin{array}{l}\text { Dietary protein metabolism by gut microbiota and its } \\
\text { consequences for chronic kidney disease patients }\end{array}$ & Human & CKD & 2013 & Review & 17 \\
\hline 4 & Chronic kidney disease alters intestinal microbial flora & Human & CKD/ESRD & 2013 & Original research & 5 \\
\hline 5 & $\begin{array}{l}\text { The gut microbiome, kidney disease, and targeted } \\
\text { interventions }\end{array}$ & Human & CKD & 2013 & Review & 19 \\
\hline 8 & $\begin{array}{l}\text { Abdominal contributions to cardiorenal dysfunction in } \\
\text { congestive heart failure }\end{array}$ & Human & Cardiorenal & 2013 & Review & 22 \\
\hline 9 & $\begin{array}{l}\text { The colon: an overlooked site for therapeutics in dialysis } \\
\text { patients }\end{array}$ & Human & CKD & 2013 & Review & 23 \\
\hline 10 & $\begin{array}{l}\text { CKD impairs barrier function and alters microbial flora of } \\
\text { the intestine: a major link to inflammation and uremic } \\
\text { toxicity }\end{array}$ & Human & $\mathrm{CKD}$ & 2012 & Review & 24 \\
\hline 11 & $\begin{array}{l}\text { Early exposure to germs modifies kidney damage and } \\
\text { inflammation after experimental ischemia-reperfusion injury }\end{array}$ & Mouse & AKI & 2009 & Original research & 4 \\
\hline
\end{tabular}

overlapping pathophysiological mechanisms such as inflammation, apoptosis, hemodynamic changes, and oxidative stress [2]. AKI can also increase the incidence of end-stage renal disease (ESRD) and the risk of developing chronic kidney disease (CKD). Recent data indicate that intestinal microbiota can modify AKI. In this minireview, we will discuss the current information available on intestinal microbiota in the context of kidney diseases and make suggestions for future research.

\section{Renal Effects of Intestinal Microbiota}

The 'hygiene hypothesis' postulates that a lack of early exposure to infectious agents, symbiotic microorganisms, and parasites increases the susceptibility to immune-me- diated diseases by suppressing the natural development of immune tolerance [3]. Based on this concept, Jang et al. [4] performed the initial study examining the effect of gut microbiota on ischemia-induced AKI. Germ-free status led to significantly worse structural and functional renal injuries plus cellular and soluble inflammation after AKI. Germ-free mice with AKI had higher serum creatinine levels and increased tubular injury compared to control mice. Repopulation of germ-free mice with wild-type (WT) gut microbiota (conventionalization) protected them from the higher injury susceptibility and transformed them closer to AKI in control mice. Analysis of germ-free kidneys at baseline (no ischemia-reperfusion injury) showed high IFN- $\gamma$ and low IL-4 levels as compared to WT mice. This suggested that kidneys of germfree mice may have a T helper 1 (Th1) type response sim- 
Fig. 1. Kidney-intestinal microbiota cross talk depends on microbe-generated and kidney-generated factors. A balance between symbionts and pathobionts ensures intestinal barrier integrity and normal kidney function. Similarly, healthy kidneys communicate with intestinal microbiota through cellular and molecular signals to ensure a normal kidney-gut microbiota homeostasis. Breakdown of this balance due to either AKI or overgrowth of pathobionts in the intestine promotes loss of intestinal barrier integrity, activation of immune cells, and cytokine secretion that further deteriorates kidney function and symbiosis. DC $=$ Dendritic cells. Figure modified from Anders et al. [18].

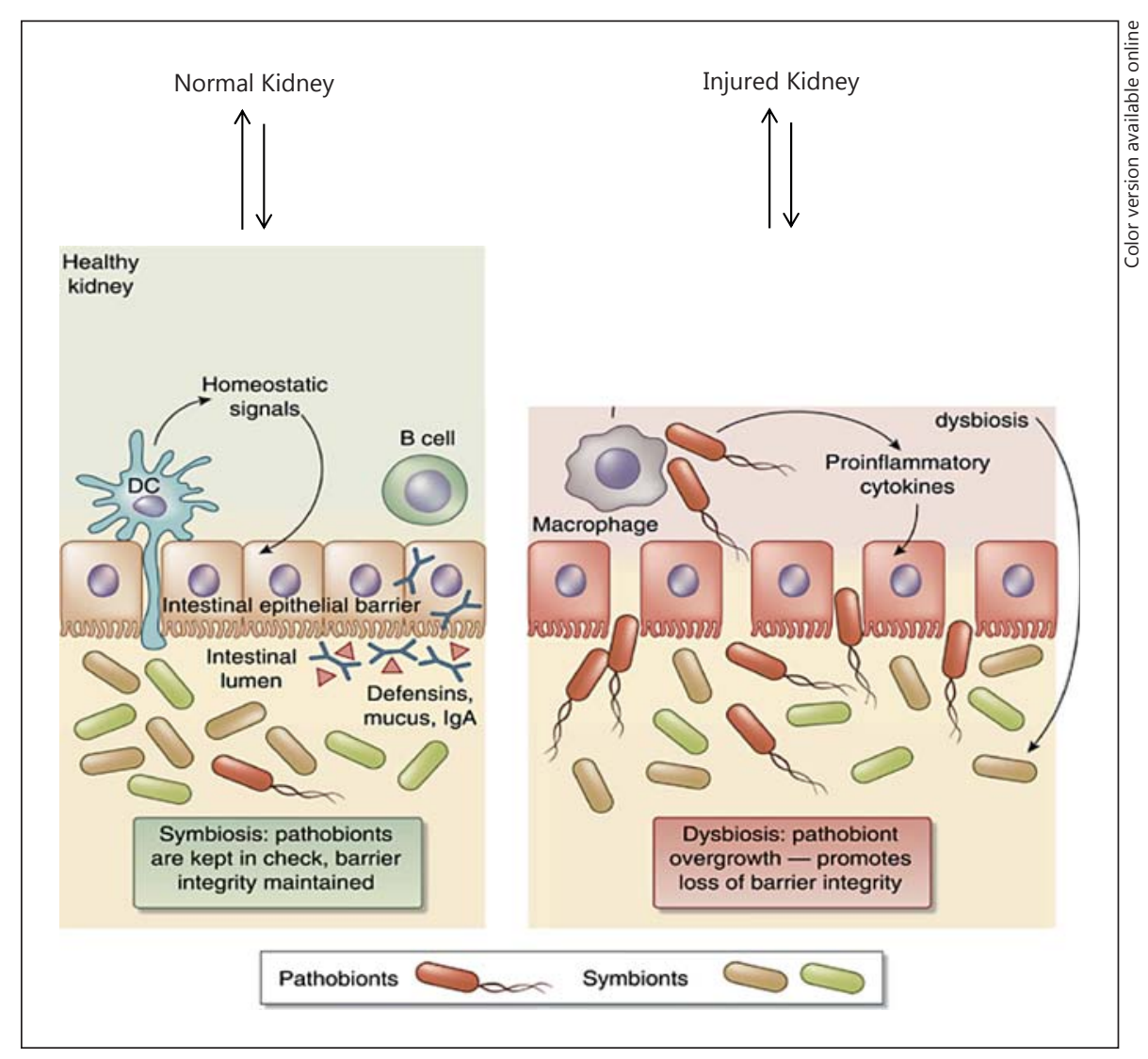

ilar to that seen in autoimmune disease. It was further postulated that a reduced stimulation of regulatory $\mathrm{T}$ cells during development may be one of the reasons for the excessive damage observed in germ-free mice; however, no significant difference in regulatory $\mathrm{T}$ cell population between germ-free and WT mice was observed.

Changes in intestinal microbiota have also been found in studies on AKI-to-CKD transition and ESRD [5]. In a recent study by Vaziri et al. [5], uremia and dietary and pharmacologic interventions were found to alter intestinal microbes in ESRD patients. They found marked differences in the abundance of 190 bacterial operational taxonomic units (a DNA sequence that represents a species or group of similar species) between ESRD and control patients. They also studied this in rats and found a difference in the abundance of 175 operational taxonomic units between uremic and control animals. Vaziri et al. [5] speculated that uremia directly or indirectly affects the composition of gut microbiota, and translocation of bacterial products across the leaky intestinal barrier activates the immune system, resulting in systemic inflammation associated with ESRD and CKD. Additional evidence suggests that microbial dysbiosis (imbalanced microbial dynamics) and bacterial translocation to the systemic and lymphatic circulation contribute to microinflammation in ESRD patients and experimental uremia in rats [6]. McIntyre et al. [7] showed that circulating bacterial endotoxin/LPS levels increase along with the stages of CKD, and they are highest in patients on hemodialysis or peritoneal dialysis. Similar metabolic changes can be speculated to induce dysbiosis in AKI; however, the exact mechanisms are unknown.

\section{Gut Microbiota-Immune System Interaction in Kidney Disease}

It is believed that the complex and dynamic interactions between microbiota and humans are the culmination of nearly half a billion years of coevolution. The emergence of adaptive immunity in vertebrates sets the stage for an advanced symbiotic relationship with the intestinal microbiota and affords a mechanism to tailor specific immune responses to diverse types of microbes. 
Breakdown of this evolutionary relationship, leading to dysbiosis, may be a significant cause of disease (fig. 1) [8]. In immunocompetent mice, intestinal colonization stimulated the production of secretory IgA, the differentiation of effector Th1, Th2, and Th17 cells, and the development of regulatory T cells [9]. Although the exact impact of gut microbiota on the host immune system and the kidney is still being unraveled, Jang et al. [4] demonstrated the important finding that germ-free mice kidneys had higher NKT cell numbers at baseline but did not have differences in the percentages of total T cells, CD4 cells, CD8 cells, and total B cells [4]. Furthermore, IR-induced AKI resulted in a greater number of CD8 T cells trafficking into postischemic kidneys in germ-free mice, which resulted in an overall increase in total $\mathrm{T}$-cell trafficking. There was no difference in the percentages of total CD4 T cells, total B cells, and NKT cells among kidney mononuclear cells isolated from the two groups. A recent study by Wingender et al. [10] found that intestinal microbes induce phenotypic and functional changes in invariant natural killer T (iNKT) cells. They found that the introduction of Sphingomonas bacteria into germ-free mice fully established phenotypic maturity in iNKT cells, whereas the introduction of Escherichia coli did not. Furthermore, they found that iNKT cells responded to microbes independently of Toll-like receptor and T-cell receptor signaling. Additional data suggest that Cd1d, an MHC class I-related protein, and NKT cell activation through sphingolipids regulate intestinal colonization [11]. The current understanding of the immunomodulatory effects of intestinal microbiota in CKD/ESRD patients is increasingly recognized in the polarization of T-cell subsets and natural killer T cells [12]. Immunomodulatory effects of the intestinal microbiota in CKD/ESRD may include the induction of Th17 cells that can drive immunopathology, similar to that observed by Lee et al. [13] in the central nervous system.

\section{Molecular Mechanism of Microbiota-Induced Kidney Effects}

Although emerging data have clearly established the role of gut microbes in many different disease conditions and indicated the involvement of different types of immune cells responsible for phenotypic changes, there is an opportunity to elucidate molecular mechanisms to explain microbe-induced changes in the host response. Recent work by Pluznick et al. [14] demonstrated that short-chain fatty acids (SCFA) produced by intestinal microbiota, and olfactory receptor 78 (Olfr78) present in the kidney, play a critical role in microbe-induced changes in kidney function [14]. SCFA such as acetate and propionate, a subgroup of fatty acids that contain an aliphatic tail, are end products of fermentation by gut microbiota and are absorbed into the circulation. Using Olfr78-null mice, they found that Olfr78, a type of G protein-coupled receptor, is expressed in the juxtaglomerular apparatus of the kidney where it modulates renin secretion in response to SCFAs. Antibiotic treatment has been shown to reduce the biomass of gut microbiota, and it also modulates blood pressure in Olfr78 knockout mice. Furthermore, $G$ protein-coupled receptor 41 (Gpr41), another SCFA receptor, is expressed in smooth-muscle cells of small resistance vessels and appears to be responsive towards SCFA. Propionate, an SCFA shown to induce vasodilation ex vivo, produces an acute hypotensive response in WT mice. This effect is differentially modulated by disruption of Olfr 78 and Gpr41 expression. Thus, both Olfr78 and Gpr41 respond to SCFA to modulate blood pressure. However, the role of Gpr41 in AKI and its contribution to the modulation of intestinal microbiota have not been tested. Newer data show that sphingolipids produced by intestinal microbiota regulate the homeostasis of iNKT cells. Further investigation of these molecular mechanisms is required to fully clarify the role of intestinal microbiota in kidney diseases.

\section{Future Studies and Potential Therapeutic Use of Microbes in Kidney Diseases}

While microbiota is an increasingly studied area of many human diseases, there is a relative lag in microbiota-related studies in kidney diseases. Preliminary work by Peterson et al. enumerated and speciated the colonic microbial pattern after both ischemic and cisplatin-induced AKI [15]. This and other studies have led to many new questions, such as: what are the detailed effects of AKI on intestinal microbiota dynamics? Does the intestinal microbiota play a role in AKI-CKD transition and mortality rates? How does the selective repopulation of specific strains affect kidney injury and outcomes? What are the molecular mechanisms by which colonic flora signal to the kidney? What are the effects of gut microbiota on distant organs in AKI and how can diet modulate intestinal microbiota-mediated changes in kidney function? 
Current treatment options for kidney diseases are only supportive in nature, and novel approaches are required to improve kidney disease outcomes. Studies on microbiota in kidney diseases hold great potential for improving our understanding of the underlying mechanisms and developing future therapeutics.

\section{Disclosure Statement}

Generous support was provided by Anne Segerson and John Stanfill.

\section{References}

1 Qin J, Li R, Raes J, Arumugam M, Burgdorf KS, Manichanh C, Nielsen T, Pons N, Levenez F, Yamada T, Mende DR, Li J, Xu J, Li S, Li D, Cao J, Wang B, Liang H, Zheng H, Xie Y, Tap J, Lepage P, Bertalan M, Batto JM, Hansen T, Le Paslier D, Linneberg A, Nielsen HB, Pelletier E, Renault P, Sicheritz-Ponten T, Turner K, Zhu H, Yu C, Li S, Jian M, Zhou Y, Li Y, Zhang X, Li S, Qin N, Yang H, Wang J, Brunak S, Doré J, Guarner F, Kristiansen K, Pedersen O, Parkhill J, Weissenbach J; MetaHIT Consortium; Bork P, Ehrlich SD, Wang $\mathrm{J}$ : A human gut microbial gene catalogue established by metagenomic sequencing. Nature 2010;464:59-65.

-2 Bellomo R, Kellum JA, Ronco C: Acute kidney injury. Lancet 2012;380:756-766.

3 Wills-Karp M, Santeliz J, Karp CL: The germless theory of allergic disease: revisiting the hygiene hypothesis. Nat Rev Immunol 2001; 1:69-75.

-4 Jang HR, Gandolfo MT, Ko GJ, Satpute S, Racusen L, Rabb H: Early exposure to germs modifies kidney damage and inflammation after experimental ischemia-reperfusion injury. Am J Physiol Renal Physiol 2009; 297:F1457-F1465.

5 Vaziri ND, Wong J, Pahl M, Piceno YM, Yuan J, DeSantis TZ, Ni Z, Nguyen TH, Andersen GL: Chronic kidney disease alters intestinal microbial flora. Kidney Int 2013;83:308-315.

-6 Wang F, Jiang H, Shi K, Ren Y, Zhang P, Cheng S: Gut bacterial translocation is associated with microinflammation in end-stage renal disease patients. Nephrology (Carlton) 2012;17:733-738.

7 McIntyre CW, Harrison LE, Eldehni MT, Jefferies HJ, Szeto CC, John SG, Sigrist MK, Burton JO, Hothi D, Korsheed S, Owen PJ, Lai $\mathrm{KB}$, Li PK: Circulating endotoxemia: a novel factor in systemic inflammation and cardiovascular disease in chronic kidney disease. Clin J Am Soc Nephrol 2011;6:133-141. $\checkmark 8$ Maynard CL, Elson CO, Hatton RD, Weaver CT: Reciprocal interactions of the intestinal microbiota and immune system. Nature 2012; 489:231-241.

-9 Gaboriau-Routhiau V, Rakotobe S, Lécuyer E, Mulder I, Lan A, Bridonneau C, Rochet V, Pisi A, De Paepe M, Brandi G, Eberl G, Snel J, Kelly D, Cerf-Bensussan N: The key role of segmented filamentous bacteria in the coordinated maturation of gut helper $\mathrm{T}$ cell responses. Immunity 2009;31:677-689.

10 Wingender G, Stepniak D, Krebs P, Lin L, McBride S, Wei B, Braun J, Mazmanian SK, Kronenberg M: Intestinal microbes affect phenotypes and functions of invariant natural killer T cells in mice. Gastroenterology 2012;143: 418-428.

-11 Nieuwenhuis EE, Matsumoto T, Lindenbergh D, Willemsen R, Kaser A, Simons-Oosterhuis $\mathrm{Y}$, Brugman S, Yamaguchi K, Ishikawa $\mathrm{H}$, Aiba Y, Koga Y, Samsom JN, Oshima K, Kikuchi M, Escher JC, Hattori M, Onderdonk $A B$, Blumberg RS: Cdld-dependent regulation of bacterial colonization in the intestine of mice. J Clin Invest 2009;119:1241-1250.

12 Macpherson AJ, Harris NL: Interactions between commensal intestinal bacteria and the immune system. Nat Rev Immunol 2004;4: 478-485.

13 Lee YK, Menezes JS, Umesaki Y, Mazmanian SK: Proinflammatory T-cell responses to gut microbiota promote experimental autoimmune encephalomyelitis. Proc Natl Acad Sci USA 2011;108:4615-4622.

14 Pluznick JL, Protzko RJ, Gevorgyan H, Peterlin Z, Sipos A, Han J, Brunet I, Wan LX, Rey F, Wang T, Firestein SJ, Yanagisawa M, Gordon JI, Eichmann A, Peti-Peterdi J, Caplan MJ: Olfactory receptor responding to gut $\mathrm{mi}-$ crobiota-derived signals plays a role in renin secretion and blood pressure regulation. Proc Natl Acad Sci USA 2013;110:4410-4415.

15 Peterson DA, Chen Y, Noel S, Bandapalle S, Martina-Lingua MN, White JR, Hamad ARA, Rabb H: Acute kidney injury in mice induces specific changes in gut microbiota. J Am Soc Nephrol 2013;24:638A.
16 Fricke WF, Maddox C, Song Y, Bromberg JS: Human microbiota characterization in the course of renal transplantation. Am J Transplant 2014;14:416-427.

17 Mafra D, Barros AF, Fouque D: Dietary protein metabolism by gut microbiota and its consequences for chronic kidney disease patients. Future Microbiol 2013;8:1317-1323.

18 Anders HJ, Andersen K, Stecher B: The intestinal microbiota, a leaky gut, and abnormal immunity in kidney disease. Kidney Int 2013; 83:1010-1016.

19 Ramezani A, Raj DS: The gut microbiome, kidney disease, and targeted interventions. J Am Soc Nephrol 2014;25:657-670.

20 Soulage CO, Koppe L, Fouque D: Proteinbound uremic toxins: new targets to prevent insulin resistance and dysmetabolism in patients with chronic kidney disease. J Ren Nutr 2013;23:464-466.

21 Mafra D, Barros AF, Fouque D: Dietary protein metabolism by gut microbiota and its consequences for chronic kidney disease patients. Future Microbiol 2013;8:1317-1323.

22 Verbrugge FH, Dupont M, Steels P, Grieten L, Malbrain M, Tang WH, Mullens W: Abdominal contributions to cardiorenal dysfunction in congestive heart failure. J Am Coll Cardiol 2013;62:485-495.

23 Poesen R, Meijers B, Evenepoel P: The colon: an overlooked site for therapeutics in dialysis patients. Semin Dial 2013;26:323-332.

24 Vaziri ND: CKD impairs barrier function and alters microbial flora of the intestine: a major link to inflammation and uremic toxicity. Curr Opin Nephrol Hypertens 2012;21:587592.

25 Ranganathan N, Patel BG, Ranganathan P, Marczely J, Dheer R, Pechenyak B, Dunn SR, Verstraete W, Decroos K, Mehta R, Friedman EA: In vitro and in vivo assessment of intraintestinal bacteriotherapy in chronic kidney disease. ASAIO J 2006;52:70-79. 